1. FCPS (Pak), FRCS (UK) Associate Professor

General Orthopaedic Surgeon Orthopaedic Department

$\mathrm{CMH}$ Nowshera

Correspondence Address: Dr. Fayyaz Ahmad Orfi, Consultant Ortho Surgeon. CMH Malir

fayyaz_ao@hotmail.com

Article received on: 22/03/2016

Accepted for publication: 21/06/2016

Received after proof reading: 08/08/2016

\title{
FRACTURE SHAFT OF FEMUR IN CHILDREN; MANAGED WITH EXTERNAL FIXATION - A COMPARATIVE STUDY OF 31 CASES \\ fayyaz_ao@hotmail.com
}

\section{Dr. Fayyaz Ahmad Orfi ${ }^{1}$, Dr. Saira Shakeel ${ }^{2}$, Dr. Irtiza Bhutta ${ }^{3}$}

\begin{abstract}
This study was carried out to check the efficacy of external fixators as compared to conservative management in treating fracture shaft of femur in children from 2 to 8 years. Fracture shaft of femur in this age group are usually managed with traction for 2-3 weeks followed by hip spicca of 3-4 weeks. It is difficult to achieve good reduction by traction. This is not well tolerated by children. Hospital stay is prolonged. Perenial hygiene is difficult and pressure sores are common. LLD (limb length discrepancy), knee stiffness and gait changes are the long term complications associated with conservative management. ${ }^{6}$ We managed 31 cases of fracture shaft of femur in 30 children from the age of 2-8 years with external fixators (ex-fix) and compared the results with 24 cases of fracture femur managed with traction and hip spicca. Study design: Prospective study. Tertiary care hospitals of military at Muzaffarabad, Kharian and Malir. Period: Sep 2008 to Mar 2015. Material \& Methods: Informed consent was obtained. Children from 2 to 8 years were included in this study. AO External fixator with 3.5 $\mathrm{mm}$ shanze screws was used with 2 screws on each side of fracture. External fixators were removed after 8 weeks in most $(>90 \%)$ of the cases. Patients were discharged on $1^{\text {st }}$ postop day. Results: Observations were made during hospital period and then fortnightly and a minimum follow up of 6 months was done. Union was assessed clinically and on X-rays (3 surfaces union). Observations made regarding reduction achieved, complications of procedure and compliance of children. Any LLD, knee stiffness and gait abnormality were noted during the 6 months of follow up and compared with 24 cases managed conservatively (control group).
\end{abstract}

Key words: $\quad$ Fracture shaft of femur, Ex-Fix (external fixators), LLD (limb length discrepancy), DCP (dynamic compression plate), LCP (locking compression plate), Flexible I/M (intramedullary) Nails.

Article Citation: Orfi FA, Shakeel S, Bhutta I. Fracture shaft of femur in children; managed with external fixation - a comparative study of 31 cases. Professional Med J 2016;23(8):985-990. DOI: 10.17957/TPMJ/16.3366

\section{INTRODUCTION}

Fracture shaft of femur in children are treated in different ways. Children less than 2 years are generally treated with spicca or gallows traction. Displaced fractures of shaft of femur in children of 2-8 years are managed with initial traction of 2-3 weeks followed by hip spicca for 3-4 weeks. Other modalities available in this group are DCP, LCP, Flexible I/M nailing and External fixators ${ }^{2}$. Rigid static I/M nailing can be safely done after 14 years of age. External fixators are generally reserved for open or severely communitted fractures. In this study we used external fixation in all sorts of fracture shaft of femur in children from 2-4 years as a final mode of treatment and compared the results with traditional conservative treatment of traction and hip spicca. Observations were made regarding clinical and radiological union, complications of the procedure, patient's compliance, LLD, knee stiffness and gait problems. A minimum follow up of 6 months was done in all cases.

\section{MATERIAL AND METHODS}

A total of 31 femoral fractures (all types) were fixed with External fixators, with and without inter fragmentary $\mathrm{K}$ wires/screws, in 30 children from the age of 02 years to 08 years, from September 2008 to March 2015 (6 years and 6 months). In externally fixed group 29 cases had unilateral femoral fractures while one case was having bilateral femoral fractures which were fixed with bilateral $\mathrm{AO}$ fixators. It was a randomized prospective comparative study, conducted at $\mathrm{CMH}$ Muzaffarabad, Kharian and Malir. Out of 
the 31 cases, in 12 cases direct inter fragmentary screw or $\mathrm{K}$ wire was also used to achieve the reduction and then External Fixator was applied under image intesifier. We used $3.5 \mathrm{~mm}$ shanze screws, 2 proximal to fracture site and 2 distal to it. Considering the small size of femur in that age group, special care was taken to avoid injury to the proximal and distal femoral epiphyses and fracture haematoma was also avoided using image. External fixator was dynamized after 6 weeks in most of the cases and was removed after 8 weeks in 29 cases. Only in 2 cases the external fixators were left in place for up to 10 weeks, as they showed relatively slow healing of fractures on X-rays. Vanishing of fracture line of 3 surfaces in AP \& Lateral views was considered as radiological union. Twenty four cases were managed conservatively and observations made. This group was used as control group.

Children from the age of 2-8 years with fracture shaft of femur were included in this study.

Children with poly trauma including head, chest or abdominal injuries (Waddle Triad) were excluded from the study.

A minimum follow up of 6 months was done. In 24 cases of same age group fracture shaft of femur was managed conservatively which acted as a control group.

\section{RESULTS}

External fixation was applied in 31 femoral shaft fractures in 30 children (one case with bilateral femoral fractures) while conservative treatment (traction followed by hip spicca) was carried out in 24 cases. In external fixation group 19 were male and 11 female. While in conservative group 15 were male and 9 female. Average age in external fixation group was 6.8 years while in conservative group was 5.6 years. Average duration of treatment was 8.1 weeks in external fixation group and 7.8 weeks in conservative group.

In external fixation group good reduction was achieved in all cases (100\%) under image. In conservative group good reduction could be achieved only in $16.7 \%$ of cases. There were 6 cases $(20 \%)$ of pin tract infection in external fixation group as compared to none in conservative group. But there were 10 cases $(41.7 \%)$ who develop pressure sores because of traction or hip spicca. This complication was not seen in external fixation group. Patient compliance was good in $96.7 \%$ of cases in external fixation group and only $16 \%$ in conservative group. All cases with external fixation show good perineal hygiene while it was unsatisfactory in $70.8 \%$ cases with hip spicca. Early mobilization with partial weight bearing within first week was achieved in $96.7 \%$ cases treated with external fixation while none of the case of conservative group could be mobilized within first week of treatment. Average period of admission in external fixation group was 1-2 days as compared to more than 3 weeks in conservative group.

There was not much difference in period in which radiological union was achieved. It was 7.8 weeks in external fixation group as compared to 6.9 weeks in conservatively managed group. In late complications only one case (3.3\%) has more than $1 \mathrm{~cm}$ of LLD in external fixation group while it was present in $79.2 \%$ cases of conservative group. Mild knee stiffness was present in $13.3 \%$ cases of external fixation as compared to $54.2 \%$ cases of conservative group. At the end of 6 months gait abnormalities could be observed in only 3 cases $(10 \%)$ as compared to 16 cases $(66.7 \%)$ of conservative group. Refracture occurred in one femoral fracture in the case of bilateral femoral managed with external fixation after 3 months of injury. It was then managed with internal with DCP.

\begin{tabular}{|l|c|c|}
\hline & $\begin{array}{c}\text { External } \\
\text { Fixators (30 } \\
\text { cases) }\end{array}$ & $\begin{array}{c}\text { Traction/Hip } \\
\text { Spicca (24 cases) }\end{array}$ \\
\hline Male & $19(63.3 \%)$ & $15(62.5 \%)$ \\
\hline Female & $11(36.7 \%)$ & $09(37.5 \%)$ \\
\hline Average Age & 6.8 years & 5.6 years \\
\hline $\begin{array}{l}\text { Average Duration } \\
\text { of Treatment }\end{array}$ & 8.1 weeks & 7.8 weeks \\
\hline \multicolumn{2}{|c|}{ Table-I. Study Table-I. Study } \\
\hline
\end{tabular}




\begin{tabular}{|l|c|c|}
\hline & $\begin{array}{c}\text { External } \\
\text { Fixators (30 } \\
\text { cases) }\end{array}$ & $\begin{array}{c}\text { Traction/Hip } \\
\text { Spicca (24 } \\
\text { cases) }\end{array}$ \\
\hline $\begin{array}{l}\text { Reduction } \\
\text { achieved Good }\end{array}$ & $100 \%$ & $16.7 \%$ \\
\hline Pin-tract infection & $6(20 \%)$ & $0 \%$ \\
\hline Pressure sores & $0 \%$ & $10(41.7 \%)$ \\
\hline $\begin{array}{l}\text { Good Patient } \\
\text { compliance }\end{array}$ & $29(96.7 \%)$ & $3(12.5 \%)$ \\
\hline $\begin{array}{l}\text { Pperineal hygiene } \\
\text { problem }\end{array}$ & $0 \%$ & $17(70.8 \%)$ \\
\hline $\begin{array}{l}\text { Early mobilization } \\
\text { achieved } \\
\text { (15t week) }\end{array}$ & $29(96.7 \%)$ & $0 \%$ \\
\hline Admission period & $1-2$ days & 3 weeks + \\
\hline \multicolumn{2}{|c|}{ Table-Il. Results and Observations } \\
\hline
\end{tabular}

\begin{tabular}{|l|c|c|}
\hline & $\begin{array}{c}\text { External } \\
\text { fixators (30 } \\
\text { cases) }\end{array}$ & $\begin{array}{c}\text { Traction/ Hip } \\
\text { Spicca (24 } \\
\text { cases) }\end{array}$ \\
\hline LLD $>1 \mathrm{~cm}$ & $1(3.3 \%)$ & $19(79.2 \%)$ \\
\hline Knee stiffness & $4(13.3 \%)$ & $13(54.2 \%)$ \\
\hline $\begin{array}{l}\text { Gait abnormalities } \\
\text { (at 6 month) }\end{array}$ & $3(10 \%)$ & $16(66.7 \%)$ \\
\hline $\begin{array}{l}\text { Union achieved } \\
\text { (radiological) }\end{array}$ & 7.8 weeks & 6.9 weeks \\
\hline $\begin{array}{l}\text { Re-fracture (within } \\
\text { 6 months) }\end{array}$ & $01(3.3 \%)$ & $0 \%$ \\
\hline \multicolumn{2}{|c|}{ Table-III. Complications } \\
\hline
\end{tabular}
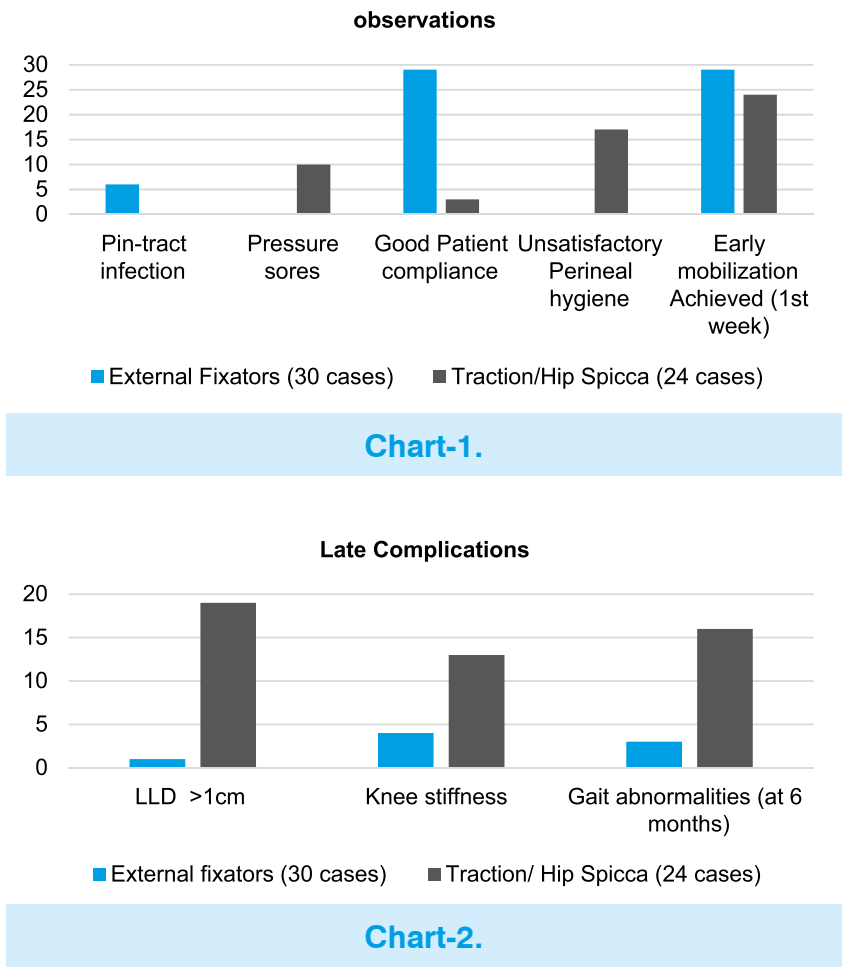

\begin{tabular}{|l|c|c|}
\hline & $\begin{array}{c}\text { External } \\
\text { fixators (30 } \\
\text { cases) }\end{array}$ & $\begin{array}{c}\text { Traction/ Hip } \\
\text { Spicca } \\
\text { (24 cases) }\end{array}$ \\
\hline LLD $>1 \mathrm{~cm}$ & $1(3.3 \%)$ & $19(79.1 \%)$ \\
\hline Knee stiffness & $4(13.3 \%)$ & $13(54.2 \%)$ \\
\hline $\begin{array}{l}\text { Gait abnormalities } \\
\text { (at 6 months) }\end{array}$ & $3(10 \%)$ & $16(66.7 \%)$ \\
\hline $\begin{array}{l}\text { Union achieved } \\
\text { (radiological) }\end{array}$ & 7.8 weeks & 6.9 weeks \\
\hline $\begin{array}{l}\text { Re-fracture (within } \\
6 \text { months) }\end{array}$ & $01(3.3 \%)$ & $0 \%$ \\
\hline \multicolumn{2}{|c|}{ Table-III. Complications } \\
\hline
\end{tabular}

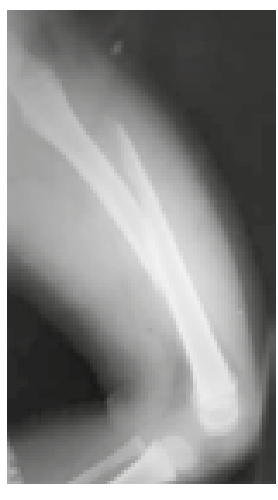

Figure-1

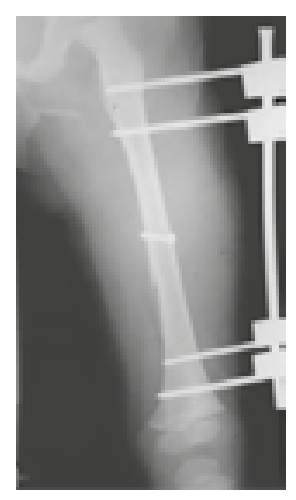

Figure-2

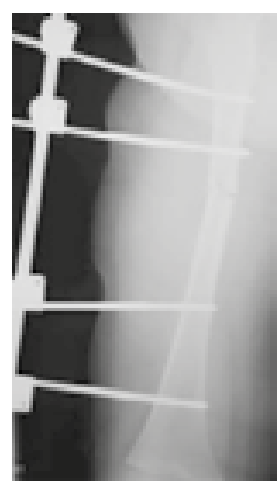

Figure-3

\section{DISCUSSION}

Fracture shaft of femur in children accounts for about $2 \%$ of all he fractures in paediatric population. ${ }^{13}$ It usually occurs after a severe trauma and may be associated with other severe injuries like head injuries. Rang described a Waddle triad of femoral shaft fracture, head injury and intra-abdominal or thoracic injury after accidents. However in our study we included isolated single or double femoral shaft fractures from the age of 2 to 8 years. Fat embolism is one of the serious complications which may occur after femoral fracture specially if associated with poly trauma. Femoral fractures are hard to miss 
on examination. Limb deformity pain, swelling, crepitus, abnormal movements, adduction of limb along with external rotation and shortening of limb are typically present. X-rays are confirmatory but the child should be made pain free and adequate splintage of the fractured limb should be done before X-rays examination. Treatment of paediatric femoral shaft fractures has following goals ${ }^{13}$ :

- Anatomical reduction but angulation of $30^{\circ}$ may be acceptable in small kids.

- maintenance of reduction until fracture is united

- minimization of complications associated with injury and its treatment

- good patient compliance to the treatment

- minimal hospital stay

- early mobilization of the patient

- minimum LLD, gait problems and knee stiffness

- treatment should not interfere with the growth epiphysis of the femur

Most important factors determining the outcome of treatment include age of the child, type of fracture, degree of displacement of fracture segments, time lag between treatment and injury and other associated injuries. Femoral shaft fracture can be open or closed. Configuration of fracture can be transverse, oblique, spiral or communitted. Paediatric femoral shaft fractures have some differences from those occurring in adults. In children these fractures heal rapidly because of rich double blood supply and biologically more active periosteum. ${ }^{11}$ Femoral shaft fractures usually occur after high energy trauma. Pathological fractures are less common in paediatric age group. About $4 \%$ of fractures of femur are pathological. Underlying conditions may include osteogenesis imperfecta, aneurismal bone cyst, unicamryl bone cyst, nonossifying fibroma or generalized osteopenia. Children have greater potential of healing and remodelling. Angular deformity up to $30^{\circ}$ may be acceptable but rotational deformity is not corrected by remodelling. ${ }^{11}$ There is tendency of overgrowth in a fractured femur in children after union because of stimulation of growth plate. This may result in lengthening of the fractured limb at later stage. Hence some experts say that some degree of overlap/impaction $(1 \mathrm{~cm}$ ) may not only be acceptable rather desirable. ${ }^{9}$ The presence of ossification centres modifies the choice of internal fixation of femoral shaft fractures in children to avoid iatrogenic injury to these centers. Proximal femur has two growth centers and together they contribute $30 \%$ of the length of femur and $13 \%$ of the length of lower limb. ${ }^{10}$ Damage to proximal femoral epiphysis leads to shortening of the extremity. Children are at lower risk of developing pulmonary complications, especially fat embolism after femoral shaft fracture as compared to adults. Femoral shaft has rich endosteal and periosteal blood supply which anastomoses with each other therefore non-union is rarely a problem in children. ${ }^{11}$ Femoral head epiphysis is supplied by the lateral branches of medial femoral circumflex vessels. The artery of ligamentum teres does not contribute any blood supply until the age of 8 years. Longitudinal and peripheral growth of femoral shaft occurs by endochondral ossification.

Usual cause of femoral fracture between 3 to 8 years is a fall but child abuse should not be ruled out. In adolescent group road traffic accident is the usual cause. It is twice as common among boys as compared to girls but in our study the difference was less significant. Conservative treatment of fracture shaft of femur usually involves weeks of immobility followed by weeks of rehabilitation. In conservative treatment, after initial period of traction, plaster of Paris cast spicca is applied. It involves long periods of home confinement and difficult to achieve good anatomical reduction. Angular deformities are common followed by shortening or sometimes lengthening of the involved limb. Reduction initially achieved can be lost during treatment. Patient compliance is poor and it is difficult to maintain good perineal hygiene. Long term follow up shows longer periods of rehabilitation are required and knee stiffness and gait problems are not uncommon.

In recent decades, for the aforementioned reasons, more and more fracture shaft of femur in 
children are being treated with open method or with external fixation. Modes of internal fixation include plating (Dynamic Compression Plates or Locking plates), flexible intra-medullary interlocking nails or rigid intra-medullary interlocking nails. Rigid I/M nails are only reserved for kids near skeletal maturity or those who have achieved skeletal maturity. Otherwise these can damage the proximal femoral epiphysis in small kids and can cause coxavara initially and coxavalga at the later stage.

Generally from the age of 4 years to 12 years, either plating is done or flexible retrograde intramedullary nails are used. Both these procedures involve significant tissue cutting. Same level of surgery is required for removal of these implants after union and consolidation has been achieved. Cost of this type of treatment is high (including implants).

External fixators are generally used for open femoral fractures in children or if the fracture is severely communited. However this type of treatment requires less tissue cutting and satisfactory alignment is achieved if applied under image intensifier. Wound care can be done better when external fixators are in place. If properly applied, generally conversion to internal implants is not required and healing time of the fracture and consolidation is almost the same as internal implants. Dynamization of external fixater after about 6 weeks helps in achieving a strong and early union of the fracture. Pin tract infection is the commonest complication encountered in this type of treatment. But it usually settles once external fixator is removed. Removal of implant is relatively easy. Kids are mobilised early after this type of treatment and their hospital stay, cost of total treatment and rehabilitation time are much reduced. Long term follow up shows that LLD, knee stiffness and gait abnormalities are rare and patient compliance is good. These observations encouraged us to used external fixator as sole mode of treatment in all sorts of fracture shaft of femur in the age group of 2 to 8 years and we compared the results with conservative treatment.

\section{CONCLUSION}

Fractures of femur shaft are usually treated by traction and hip spicca in children. These procedures are not well tolerated. It is difficult to maintain reduction. and good perineal hygiene. Incidence of pressure sore is high, involves prolonged hospital stay and home confinement. Incidence of LLD, knee stiffness and gait changes is more. Rehabilitation period is prolonged. ORIF using plates or flexible nails are major interventions. It needs another surgery for removal of implants. Cost of internal implants is high. With external fixators rate of union is as high as with internal fixations. ${ }^{8}$ External fixators are easy to apply and minimum tissue cutting is involved. They are well tolerated by the kids. Complications are few. Pin tract infection being the most common. LLD, knee stiffness and gait abnormalities are rare. ${ }^{8,9}$ They can be removed easily under sedation. Long term results are good. Managing femoral shaft fractures with external fixation in children from 2 to 8 years gives better results as compared to conservative treatment of traction and hip spicca.

Copyright@ 21 June, 2016.

\section{REFERENCES}

1. Blasier RD, Aronson J, Tursky FA. External fixation of Paediatric femur fractures. J Paed Ortho. 1997 MayJune; 17 (3): 342-6.

2. Baron,E Sagiv S, Porat S. External fixation or flexible $\mathrm{I} / \mathrm{M}$ nailing for femoral shaft fractures in children. $J$ bone joint surg 1997.

3. Guaracy CF, Alcen GC, Helen CG et al. External fixation in femur fractures in children. ActaortopedicaBrasileira.2005; Vol 13 (1) Sao Paulo.

4. Flynn JM, Schwend RM. Management of Paediatric femoral shaft fractures. J Am Acad of Orthop Surg.2004 Sep/Oct; 12:347-59.

5. Kong $\mathrm{H}$, Sasharwal S. External fixation for closed paediatric femoral shaft fractures. Where are we now? Clinorthop Res. 2014 Dec; 472(12): 3814-22. Doi: $10.1007 / \mathrm{s} 199-014-35545$.

6. Sundus, J.O. Browne RH, Mounen JF, Ravey EM et al. Treatment of femoral fractures in children by paed orthopaedist; result of a 1998 survey. (The Paediatric Orthopaedic Society of N. America. Evidence analysis workgroup) J Paed Ortho.2001 July/Aug; Vol 21- issue 


\section{4:436-441.}

7. Narayanan UG, Hyman JE, Umi G , Joshua E, Wain Wright, Andrew M; Rang, Mercer, Alman, Benjamin A. Complication of elastic stable intra medullary nail fixation of paediatric femoral fractures and how to avoid them. J Paed Ortho. 2004 Vol 24 (4); 363-69.

8. Hedin H, Hjorth K, Larson S, Nilsson S. Radiological outcome after external fixation of 97 femoral shaft fractures in children. Injury .2003 May; 34(4):287-92.

9. Hougards K. Femoral shaft fractures in children: a prospective study of overgrowth phenomenon. Injury. 1989 May; 20(3):170-2.
10. Nordm S, Ros MD,Faisham WI. Clinical measurement of longitudinal femoral overgrowth following fracture in children. Singapore Med J. 2001 Dec; 42(12):563-5.

11. Green WB Displaced fracture of the femoral shaft in children. Unique features and therapeutic optionsClin Ortop Res.1998Aug; (353): 86-89.

12. Prince DE, Herzenberg JE, Standard SC, Paley D. Lengthening with external fixation is effective in congenital femoral deficiency. Clin Orthop Relat Res. 2015 Oct; 473(10):3261-2.

13. Karthic S, Dennis G. Paediatric femur fractures. Medscape 2015.

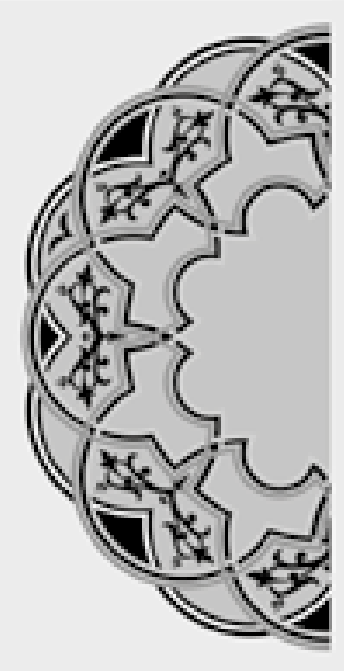

\section{"The most dangerous liars are the ones who are convinced that they are telling the truth do you know one of these."}

Unknown

\section{AUTHORSHIP AND CONTRIBUTION DECLARATION}

\begin{tabular}{|c|c|c|c|}
\hline Sr. \# & Author-s Full Name & Contribution to the paper & Author $=\mathbf{s}$ Signature \\
\hline $\begin{array}{l}2 \\
3\end{array}$ & $\begin{array}{l}\text { Dr. Fayyaz Ahmad Orfi } \\
\text { Dr. Saira Shakeel } \\
\text { Dr. Irtiza Bhutta }\end{array}$ & $\begin{array}{l}\text { Concept, Design } \\
\text { operating surgeon } \\
\text { Data collection research } \\
\text { work } \\
\text { Editing proof reading }\end{array}$ & 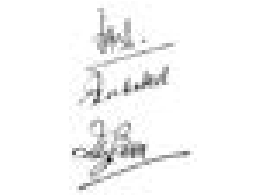 \\
\hline
\end{tabular}

